\title{
Intact Epithelial Reticular Basement Membrane Length to Total Epithelial Reticular Basement Membrane Length Ratio Measurement
}

\author{
National Cancer Institute
}

\section{Source}

National Cancer Institute. Intact Epithelial Reticular Basement Membrane Length to Total

Epithelial Reticular Basement Membrane Length Ratio Measurement. NCI Thesaurus. Code $C 156547$.

The determination of the ratio of intact epithelial reticular basement membrane length compared to total epithelial reticular basement membrane length present in a sample. The measurement may be expressed as a ratio or percentage. 